3. A greater amount of current could be supplied by a cell with one reversible and another irreversible electrode, when an alternating current plays in the circuit.

4. In cells like $\mathrm{Cd}-\mathrm{ZnCl}_{2}-\mathrm{Hg}, \mathrm{Cd}-\mathrm{ZnCl}_{2}-\mathrm{Pt}$, etc., the $\mathrm{E} . \mathrm{M}$. F. of $\mathrm{Hg}$ or $\mathrm{Pt}$ electrode approaches the value of the zinc electrode on the passage of the alternating current.

5. In perfectly reversible electrolytic cells the alternating current has no action when impressed on the cell along with a direct current.

6. But if the electrolytic cell be irreversible, the alternating current greatly increases the current strength through the circuit.

7. This increase in current strength is due to the diminution in the back electromotive force of polarization.

8. This diminution in the discharge potential is also observed, in electrolytic cells consisting of two cathodes and two anodes, the alternating current playing between the anodes or the cathodes, but not passing through the whole circuit.

In conclusion, my best thanks are due to Professors P. C. Rây, and J. B. Bhaduri, for their interest and encouragement.

Calcutra, inda.

[CONTRIBUtion fRom the Chamical, Laboratory of Harvard Untversity.]

\title{
PROPERTIES OF SIIVER IODIDE INTERPRETED IN RELATION TO RECENT THERMODYNAMIC CONCEPTIONS.
}

By GrinNell Jones and MingR Louts Hartmans.

Received February 8, 1915.

This paper presents the results of an experimental study of the most important thermodynamic properties of silver iodide, interpreted in the light of Richards' Theory of Compressible Atoms. These results have also furnished a quantitative test of the so-called Nernst Heat Theorem. They support the former theory, but not the latter.

The mathematical physicists who developed the kinetic theory of gases and liquids, in order to simplify the exceedingly complex mathematiical analysis, were forced to assume that atoms are incompressible. Theodore William Richards ${ }^{1}$ has, however, presented an array of facts and arguments which show that atoms and molecules are, in reality compressible, or, in other words, that the volume of the atoms is changeable, and dependent on the pressure exerted upon them, whether due to ( $I$ ) external force, (2) the attraction between molecules of the same kind, which is manifested in cohesion, (3) the attraction of the atoms within the

1 Professor Richards, in a Presidential Address for the American Chemical Society, "The Present Aspect of the Hypothesis of Compressible Atoms" (THis Journal, 36, 2417 (Dec., 1914)), gives a summary of the results obtained and a complete bibliography. 
molecules, which is manifested in chemical affinity. Richards has shown also that the free space within the molecules has been commonly greatly overestimated, and that it is in all probability very small.

The old kinetic hypothesis, with its added assumption that the volume of the atom is unchangeable, accounts for the fact that the coefficient of expansion of all substances (with five known exceptions) is positive by the assumption that, with rising temperatures, the increased violence of the molecular collisions causes an increase in the free space between the molecules. A decrease in volume with rise in temperature, $i$. e., a negative coefficient of expansion, is, however, entirely inexplicable on this conception of the nature of the atom. But the coefficient of expansion of silver iodide is negative. ${ }^{1}$

The senior author of this paper has attempted to account for this negative coefficient of expansion of silver iodide by an extension of this hypothesis of atomic compressibility. It was suggested ${ }^{2}$ that the change in volume which occurs when a solid is heated may be regarded as made up of at least three parts:

I. An increase in the intramolecular free space. This effect is, howover, probably small, since the free space itself is probably very small.

2. An increase in the volume of the molecules due to a decrease in the cohesion.

3. A change in the volume of the atoms due to a change in the attractive force between the molecules.

In the case of silver iodide, whose volume decreases with rise in temperature, this hypothesis led to the inference that the attractive force increases with rise in temperature, and thereby produces an increased compression great enough to outweigh the effect of the first two influences.

Although the free energy of the reaction may not give a quantitative measure of the attractive force, since a part of the work done by the attractive force or chemical affinity may be expended in producing compression of the atoms, and thereby be stored up as potential energy within the compound and not be available for outside work, nevertheless, the free energy gives the best indication we have of the attractive force, and would be expected to have the same temperature coefficient as the attractive force itself.

A computation of the temperature coefficient of the free energy by the aid of the Helmholtz equation indicated that free energy and, therefore, also, affinity does really increase with rise in temperature, and thus the deduction from the hypothesis was confirmed.

I See Grinnell Jones, ThIs Journal, 3I, I9I (1909) for a discussion of the experimental evidence for this statement, and for a brief discussion of the four other known cases of negative coefficient of expansion.

${ }^{2}$ Grinnell Jones, Loc. cit. 
The data used in these earlier computations were collected from many sources, and the errors of all of them entered into the result. ${ }^{1}$ It, therefore, seemed desirable to further test this explanation of the negative coefficient of expansion of silver iodide by direct measurement at two temperatures of the potential of an electrolytic cell, which, by its action, produces silver iodide from its elements. A detailed description of this experimental study is given in the following pages.

In order to be able to apply accurately corrections for osmotic work, and for the liquid junction potential, a knowledge of the mobilities and concentrations of all the ions in the solution, at the two temperatures involved, is required. The existing literature furnished this desired information at $25^{\circ 2}$ but for $0^{\circ}$ it was necessary to determine the mobility of $\mathrm{I}^{-}$and $\mathrm{I}_{3}{ }^{-}$ions, and the concentrations of each ion in the solutions of different strengths of potassium iodide saturated with iodine. The special investigation carried out for this purpose has recently been published. ${ }^{3}$

\section{The Free Energy of Formation of Silver Iodide.}

In order to measure the free energy of formation of silver iodide from silver and iodine, a reversible electrolytic cell was devised, which by its action forms silver iodide from the elements. The electromotive force of this cell (after making certain corrections to the observed potential) gives a measure of the tendency of the reaction to occur. The cell consisted of two halves, an iodine electrode and a silver-silver iodide electrode. The iodine electrode consisted of a platinum foil surrounded by solid iodine in a solution of potassium iodide. Some of the dissolved iodine formed the triiodide ion from the iodide ion. The silver-silver iodide electrode was made of a platinum wire covered with silver and silver iodide in a solution of potassium iodide of the same strength as that used around the iodine electrode.

The action may be considered as, first, the solution of the silver to form silver ion, but since the solution is already saturated with silver iodide, this silver ion is immediately precipitated as AgI by the excess of iodide ion in the solution. Simultaneously, an iodide ion is formed from the iodine at the platinum electrode. The result is a difference of potential, which gives a measure of the tendency of silver and iodine to combine. Proper corrections must be applied for the potential at the junction of the two halves of the cell and for the osmotic work caused by the different concentrations of iodide ions on the two sides.

Details of the Experiments.-The potentiometer used was of the usual

1 The heat of formation of silver iodide given by Thomsen was obtained very indirectly by him by the combination of a large number of thermo-chemical data, so that this result seemed especially unreliable.

"Bray and Mackay, This Journal, 32, 914 (1910).

${ }^{3}$ Jones and Hartmann, Ibid., 37, 24 I (IgI5). 
Poggendorf compensation type, constructed of standardized Leeds and Northrup decade resistance boxes. The Weston standard cell was tested by the Bureau of Standards. The potentiometer gave entire satisfaction. It was sensitive to o.oI millivolt on cells of low internal resistance, such as two similar platinum electrodes about I cm. apart in a $0.1 \mathrm{~N}$ solution of potassium iodide saturated with iodine. When using our complete silver-silver iodide-iodine cell, which had a very much greater internal resistance, readings could still be made with ease and certainty to o.r millivolt.

The cells were deeply immersed in a mixture of finely cracked ice and distilled water contained in a large Dewar tube, which was carefully covered with many inches of cloth. The rate of gain of heat from the surroundings was so slow that no stirring was necessary to maintain the temperature accurately at $0^{\circ}$. For the measurements at $25^{\circ}$, the cells were placed in a large electrically controlled thermostat, which was carefully adjusted to $25.00^{\circ}$, by the aid of a thermometer which had been calibrated at the Bureau of Standards. Since a change of ${ }^{\circ}$ in temperature changes the potential of the cell by only o. 8 millivolt, it was easy to control the temperature so accurately that no error need be feared from this source.

Preparation of Chemicals and Solutions.-Iodine and potassium iodide were prepared as described on pages 242,243 , of our first paper. ${ }^{1}$

Silver oxide was prepared from pure silver nitrate recrystallized twice from conductivity water and drained centrifugally. Barium hydroxide, found by test to be free from halogens, was dissolved in water and allowed to stand until the barium carbonate had settled. The solution was then poured through a filter into a dilute solution of the purified silver nitrate. At the end a very slight excess of the silver nitrate remained, and the precipitate was washed free from barium and nitrate. The precipitate was not dried, but was kept under water for future use.

Silver iodide was made by precipitating pure silver nitrate with pure potassium iodide in dilute solution and washing free from potassium nitrate solution. This salt was also kept moist in the form of a paste, protected from decomposition due to light.

The solutions of potassium iodide and of potassium iodide saturated with iodine were prepared as described in the first paper. The solutions were ordinarily saturated with iodine at $25^{\circ}$, and since solid iodine is precipitated readily from such solutions on cooling, the solution would adjust its own iodine content at $0^{\circ}$ when cooled. By trial it was found that this method gave the same results as when the iodine solution was saturated at $0^{\circ}$. In all cases, the platinum electrode was covered with solid iodine so that the solution must have been in equilibrium at the temperature under consideration.

${ }^{1}$ Jones and Hartmann, Loc. cit. 
Preparation of the Silver-Silver Iodide Electrodes.-The problem of preparing constant and reproducible silver electrodes was solved only after many trials and failures, which need not be described in detail. After many less satisfactory procedures had been tried, the following was found to give very good electrodes: A platinum wire was sealed into a small glass tube so that outside connection could be made through mercury in the tube. The end of the platinum wire was wound into a small spiral and carefully cleaned. Silver was then electroplated onto the platinum from a solution of silver nitrate in potassium cyanide. A very small current-about 0.005 amperes for each electrode-was used for two hours. The electrode was then carefully washed free from cyanide, and dipped into a thick paste of silver oxide and water. The silver oxide on the wire was decomposed by slowly heating in a small electric oven at from $400^{\circ}$ to $500^{\circ}$. It was found to be necessary to entirely decompose the silver oxide, or a different electromotive force was obtained. The silver oxide was applied several times and heated, until the spiral was filled with this finely divided but still coherent mass of silver. ${ }^{1}$ The electrode was next made an anode in a dilute solution of potassium iodide, and thus coated with a very thin, coherent layer of silver iodide. ${ }^{2}$ The current used in this operation was only 0.001 ampere, and the time was about two hours. The electrodes were allowed to stand in a fresh solution of potassium iodide, saturated with silver iodide, of the same strength as that in which they were to be used.

To show the reproducibility of this form of electrode, the following table will be sufficient. Electrodes 42, 44, 45 were made June 20 th; 50 and 51 were made together June 27 th; 63 and 64 were made July Ist. Nos. 42 and $5 \mathrm{I}$ had been in contact with potassium iodide containing free iodine. All had been used in various preliminary cells. These data were taken July 8th.

No. 64 against... $45 \quad 44 \quad 42 \quad 50 \quad 51 \quad 63$ Difference...... + $+0.00024-0.00002+0.00024+0.00020+0.00003+0.00013$ volt

Average difference from the mean 0.00009 volts.

Considering the diverse treatment of these electrodes before this measurement, the agreement is quite satisfactory.

The following table will show the variation of five of these electrodes, prepared at the same time and under identical conditions. The measurements were made with the electrodes dipping into a $0.1 N$ solution of potassium iodide saturated with silver iodide.

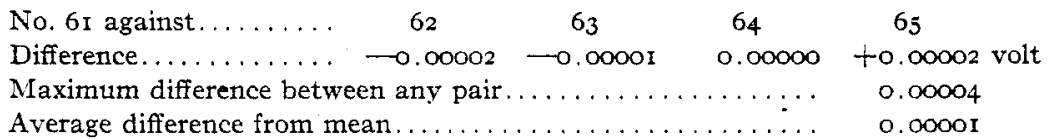

1 This procedure was used by Lewis, This Journal, 28, I66 (I906), for silver electrodes in silver nitrate solution.

${ }^{2}$ H. M. Goodwin, Z. physik. Chem., I3, 630 (1894), used this procedure with good results. 
The Iodine Electrodes.--The iodine electrodes were made after the manner described by Crotogino. ${ }^{1}$ A piece of platinum foil about I cm. square was welded to a short platinum wire. This wire was sealed through the end of a glass tube, so that electrical connection could be made through a column of mercury. The platinum wire and foil were thoroughly cleaned with acids and heated white hot before use. They were then put into a potassium iodide solution saturated with iodine.

Five electrodes made in this way at different times and used in preliminary cells gave the following results, after standing in a $0.1 N$ solution of potassium iodide saturated with iodine:

\begin{tabular}{|c|c|c|c|}
\hline $\begin{array}{lc}\text { No. } 5 \text { against. . . . . . . } & 24 \\
\text { Difference. . . . . . . . . } & -0.00055\end{array}$ & $\begin{array}{c}6 \\
-0.00006\end{array}$ & $\begin{array}{l}\text { II } \\
-0.00008\end{array}$ & $\begin{array}{l}2 \mathrm{I} \\
-0.00004 \text { volt }\end{array}$ \\
\hline $\begin{array}{l}\text { Maximum difference between any } \\
\text { Average difference from the mean. }\end{array}$ & & & $\begin{array}{l}0.00008 \\
0.00002\end{array}$ \\
\hline
\end{tabular}

Another set prepared and measured at a later time showed even better agreement. These electrodes were ignited in a gas flame to a white heat, and then allowed to stand short-circuited in a 0. I $N$ solution of potassium iodide saturated with iodine. The electrodes being close together, the internal resistance of the cell was low, and under these conditions our potentiometer was very sensitive, a change in the setting corresponding to 0.1 millivolt causing a deflection of $13 \mathrm{~mm}$. on the scale of the galvanometer. It is evident that the iodine electrodes, if properly prepared and handled, need give us no anxiety.

No. 21 against:

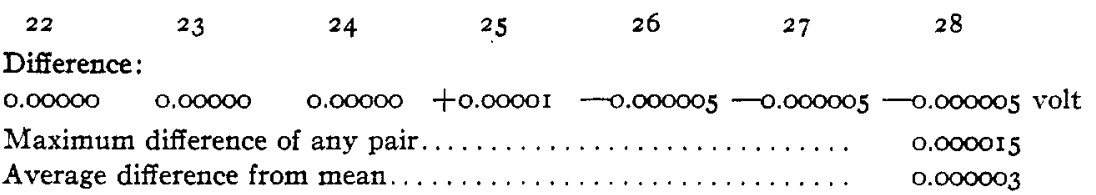

The Silver Iodide Cell.-The problem of preparing the electrodes having been solved, it now remained to find the best way to connect the two halves of the cell. The diffusion of iodine (or the triiodide ion) to the silver electrode must not occur for several days, the internal resistance of the cell must not become so great that our potentiometer would not be sensitive to 0.1 millivolt, and the conditions at the junction of the two liquids must approach, as nearly as possible, to the conditions which are assumed in the derivation of the equation, by which the potential at the liquid junction is calculated. The cells should be constant for a long time and reproducible. Cells were tried with the familiar double siphon connection, and also cells in which the connection was made in a U-tube filled with sand, but these cells were not as constant and reproducible as a cell of a much simpler construction in which the connection is made through

${ }^{1}$ Crotogino, $Z$. anorg. Chem., 24, 255 (1900). 
a ground-glass stopper. ${ }^{1}$ If the glass-grinding is very good, and the stopper firmly in place, the internal resistance is too great, and, therefore, the potentiometer not sufficiently sensitive, but by regrinding a very little with coarse carborundum, it was found to be possible to greatly increase sensitiveness of the potentiometer without causing unduly rapid diffusion of iodine to the silver electrode. Cells of this type were found to be appreciably more constant and reproducible than cells of any other type which were tried, and were used in all the final measurements. Planck, in the derivation of his formula for the potential at the boundary of two solutions, assumes that junction is sharp at the beginning, and that an intermediate layer of variable composition is produced by diffusion alone with no mechanical mixing of the solutions. This construction of the cell seems to realize this condition experimentally better than any other.

A sketch showing the construction of the type of cell which gave the most constant and reproducible results is shown in Fig. I. The large outer tube was fitted with a rubber stopper through which the inner tube was in-

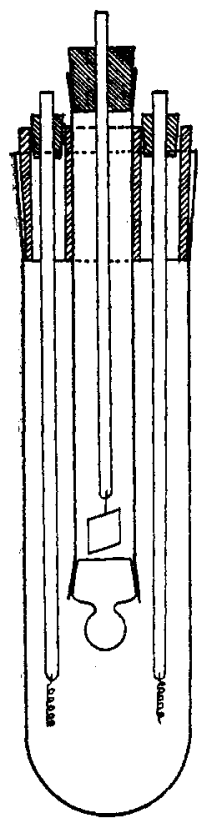

Fig. I. serted. Two holes were made in the stopper, large enough to allow the silver electrodes to be put through them, and a third small hole to allow equalization of air pressure was made. The silver electrodes were held in place by means of smaller rubber stoppers, which fitted into the holes in the main stopper. This arrangement allowed easy interchange of the electrodes without disturbing the cells. The inner tube had a ground-glass stopper at the end inside the cell. The upper end was provided with a paraffined cork stopper (which is not appreciably attacked by iodine vapors), which supported the iodine electrodes. The ground-glass stopper was held in place by a silver wire.

The large tube contained the potassium iodide solution saturated with silver iodide, and the inner tube contained the same solution saturated with iodine, and a large excess of solid iodine. In setting up the cell, the potassium iodide solution was first put in the outer tube and the saturated iodine solution, together with a large excess of solid iodine, put in the inner tube. The latter, with the large rubber stopper, was put into place as soon as the solution had wet the ground-glass joint, and the levels of the two solutions were quickly adjusted to avoid any difference of pressure. Then the iodine and silver electrodes were put in place and the whole apparatus made water proof with paraffin. It was then placed in the thermostat, and the potential measured.

${ }^{1}$ A. P. Laurie, $Z$. physik. Chem., 64, 6I $(1908)$, has used a liquid function of this kind with success. 
The potential of the cells when first set up was variable and not reproducible, but after allowing a few hours for the temperature and the condition at the boundary to adjust themselves, this uncertainty disappeared. Several of the cells containing O.I $N$ potassium iodide solution were kept at constant temperature for a week, and the potential did not vary more than 0.0002 volt, and they were apparently in good condition when the measurements were stopped. The cells containing $0.05 \mathrm{~N}$ solution were not quite so constant. Their variation was, however, not over 0.0004 volt during several days. With a pair of each kind of electrodes in a cell, it was possible to obtain check readings on the electrodes, and these seldom varied more than 0.0002 volt. In the case of the iodine electrodes it was hardly ever possible to detect any difference at all, and in the later experiments only one of these electrodes was used.

Two strengths of potassium iodide were used, 0.I $\dot{N}$ and $0.05 N$. Measurements of the potential at $0^{\circ}$ and $25^{\circ}$ were made with both strengths of solution. Tables I, II, III, IV will show measurements of typical cells under the four conditions.

Many other cells of the same type were set up, but since they behaved in a very similar way, it does not seem necessary to record the observations in detail. The accepted potential judged from each of these cells alone is given below, which records all the cells which were not subject to known error and which remained constant for a reasonable length of time. A considerable number of cells were set up which for one reason or another

Table 1.-Potential of Celil No. 4. O.I $N$ KI SOLUTION, 25.0\% IODINE ELECTRODE NO. I.

$\begin{array}{cccc}\text { Date. } & \text { Time. } & \begin{array}{c}\text { Silver } \\ \text { electrode } \\ \text { No.37. } \\ \text { Volt. }\end{array} & \begin{array}{c}\text { Silver } \\ \text { electrode } \\ \text { No.38. } \\ \text { Volt. }\end{array} \\ \text { May 2I } & \text { II:30 A.M. } & 0.7017 & 0.7016 \\ \text { May 2I } & 4: 30 \text { P.M. } & 0.7005 & 0.7003 \\ \text { May 22 } & 8: 00 \text { A.M. } & 0.6999 & 0.7001 \\ \text { May 22 } & 8: 45 \text { P.M. } & 0.7000 & 0.7002 \\ \text { May 23 } & \text { I0:30 A.M. } & 0.7000 & 0.7000 \\ \text { May 24 } & \text { I:00 P.M. } & 0.6998 & 0.7000 \\ \text { May 26 } & \text { II:00 A.M. } & 0.7001 & 0.7000 \\ \text { Accepted potential from this cell } & 0.7000\end{array}$

NoTE.-The first measurements (II:30 A.M., May 2I) were made immediately after setting up the cell, and, therefore, are not significant. Even five hours later this cell had not reached its final potential.
TAble II.-Potential of Celi, No. 31 . $0.05 N$ KI SOLUTION, $25.0^{\circ}$. IODINE ELECTRODE No. 5.

\begin{tabular}{|c|c|c|c|}
\hline $\begin{array}{l}\text { Date. } \\
1912 .\end{array}$ & Time. & $\begin{array}{c}\text { Siiver } \\
\text { electrode } \\
\text { No. } 80 . \\
\text { Volt. }\end{array}$ & $\begin{array}{c}\text { Silver } \\
\text { electrode } \\
\text { No. } 72 . \\
\text { Volt. }\end{array}$ \\
\hline July I 9 & $4: 00$ P.M. & 0.6995 & 0.6996 \\
\hline July 20 & $7: 45$ A.M. & 0.6989 & 0.6991 \\
\hline July 20 & $7: 30$ P.M. & 0.6992 & 0.699 \\
\hline July 2 I & 9:00 P.M. & 0.6992 & 0.6990 \\
\hline July 22 & I:OO P.M. & 0.6990 & 0.6991 \\
\hline July 23 & 9:0O A.M. & $0.699 \mathrm{I}$ & 0.6992 \\
\hline July 24 & 6:00 P.M. & 0.6990 & 0.699 \\
\hline July 25 & 8:00 A.M. & 0.6984 & 0.6987 \\
\hline
\end{tabular}

NoTE.-The measurements of July I th were made immediately after setting up the cell, and are, therefore, not significant. By July $25^{\text {th }}$, the sixth day, some iodine had diffused over to the silver electrodes, and these measurements are, therefore, insignificant. 
Table III.-Potential of Ceil, No. 5 . 0.I $N$ KI SOLUTION, $25.0^{\circ}$ AND $0.0^{\circ}$. IODINE ELECTRODE No. 3.

Date $\begin{array}{cc}\begin{array}{c}\text { Silver } \\ \text { electrode }\end{array} & \begin{array}{c}\text { Silver } \\ \text { electrode }\end{array} \\ \text { No. } 39 . & \text { No. } 40 . \\ \text { Volt. } & \text { Volt. }\end{array}$ Measurements at $25.0^{\circ}$ :

$\begin{array}{llll}\text { May } 21 & 8: 00 \text { P.M. } & 0.7001 & 0.7000\end{array}$

$\begin{array}{llll}\text { May } 22 & 9: 00 \text { P.M. } & 0.7001 & 0.6999\end{array}$

$\begin{array}{llll}\text { May } 23 & 10: 30 \text { A.M. } & 0.6998 & 0.6997\end{array}$

Cell put in ice after 10:30 measurement and the following measurements made at $0.0^{\circ}$ :

$\begin{array}{llll}\text { May } 23 & \text { I }: 00 \text { P.M. } & 0.6948 & 0.6948\end{array}$

$\begin{array}{llll}\text { May } 23 & 8: 00 \text { P.M. } & 0.6939 & 0.6938\end{array}$

$\begin{array}{llll}\text { May } 24 \quad I: 00 \text { P.M. } & 0.6936 & 0.6935\end{array}$

$\begin{array}{llll}\text { May } 25 & \text { 10:30 P.M. } & 0.6936 & 0.6935\end{array}$

$\begin{array}{llll}\text { May } 26 \quad 8: 00 \text { A.M. } & 0.6934 & 0.6934\end{array}$

Accepted potential from this cell at
Table IV.-Poteintial of Cell No. 35 $0.05 N$ KI SOLUTION, 0.0 $0^{\circ}$ IODINE ELECTRODE NO. 5.

$\begin{array}{ccc}\text { Silver } & \begin{array}{c}\text { Silver } \\ \text { electrode } \\ \text { No. } 80 . \\ \text { electrode } \\ \text { No. 72. } \\ \text { Volt. }\end{array} & \text { Volt. }\end{array}$

$\begin{array}{llll}\text { July } 29 & 4: 30 \text { P.M. } & 0.6922 & 0.6925\end{array}$

$\begin{array}{llll}\text { July } 30 & 8: 30 \text { A.M. } & 0.6918 & 0.6920\end{array}$

July $30 \quad 5: 30$ P.M. $\quad 0.6920 \quad 0.6920$

$\begin{array}{lllll}\text { July } & 3 \mathrm{I} & 12: 00 \mathrm{M} . & 0.6916 & 0.6919\end{array}$

Aug. I 2:00 P.M. $0.6919 \quad 0.6922$

$\begin{array}{llll}\text { Aug. } 2 & 3: 30 \text { P.M. } & 0.6918 & 0.6921\end{array}$

$\begin{array}{llll}\text { Aug. } 3 & 8: 00 \text { A.M. } & 0.692 I & 0.6918\end{array}$

Aug. $4 \quad 9: 00$ A.M. $0.692 \mathrm{I} \quad 0.6918$

Accepted potential from this

cell.................. 0.6919

Note.-Set up at room temperature at Io:00 A.M. and put into ice bath.

$25^{\circ}=0.7000 ;$ at $0^{\circ}=0.6936$

did not give constant and reproducible results. In some of these, the ground joint connecting the two halves of the cell was so imperfect that free iodine diffused through to the silver electrode too quickly. In still others, the ground joint was so perfect that the internal resistance of the cell was so great that accurate measurements were not possible. Cells of entirely different construction, with the familiar siphon connections; and cells in which the connection was made in a U-tube filled with sand were also tried, but were found to be less satisfactory and were abandoned. The accepted potentials of the cells which were constant and not influenced by known errors are given below.

\begin{tabular}{|c|c|c|c|c|c|c|c|}
\hline $\begin{array}{c}0 . \mathrm{I} \\
0^{\circ}\end{array}$ & soln. at & $\begin{array}{c}0.05 N \mathrm{~K} \\
0^{\circ}\end{array}$ & soln. at & $\begin{array}{c}0.1 N \mathrm{KI} \\
25^{\circ}\end{array}$ & soln. at & $\begin{array}{c}0.05 N \mathrm{~K} \\
25^{\circ}\end{array}$ & soln, at \\
\hline Cell No. & Volt. & Cell No. & Volt. & Cell No. & Volt. & Cell No. & Volt. \\
\hline 5 & 0.6936 & 29 & $0.692 \mathrm{I}$ & 3 & 0.7000 & 27 & 0.6993 \\
\hline IO & 0.6935 & 32 & 0.6920 & 4 & 0.7000 & 30 & 0.6992 \\
\hline 23 & 0.6936 & 33 & 0.6920 & 5 & 0.7000 & $3 I$ & 0.6992 \\
\hline Accepted & & 34 & 0.6919 & 21 & $0.700 I$ & Accepted & \\
\hline av. & 0.6936 & $\begin{array}{c}35 \\
\text { Accepted } \\
\text { av. }\end{array}$ & $\begin{array}{l}0.6919 \\
0.6920\end{array}$ & $\begin{array}{c}23 \\
\text { Accepted } \\
\text { av. }\end{array}$ & $\begin{array}{l}0.7001 \\
0.7000\end{array}$ & av. & 0.6992 \\
\hline
\end{tabular}

The Liquid Junction Potential.-Planck, ${ }^{1}$ by reasoning based on kinetic considerations, has deduced a general differential equation for the liquid junction potential between two solutions which differ in concentration by infinitesimal amounts. In order to integrate this equation between limits

1 M. Planck, Wied. Ann., 39, 161 (1890); 40, 56r (1890). 
representing the composition of the two solutions around the electrodes, Planck has made the following assumptions: ${ }^{1}$

I. The intermediate layer is produced by diffusion alone.

2. The mobility of any given ion is the same in both end solutions, and through the intermediate layer.

3. The simple van't Hoff Law $\pi=c R$ T holds.

Planck's general equation is complex, and somewhat troublesome to use, but for the special case when the total ion concentration is the same on both sides of the junction and all the ions are univalent, this reduces to the equation, ${ }^{2}$

$$
\mathrm{E}=\frac{\mathrm{RT}}{\mathrm{F}} \ln \frac{\mathrm{U}_{2}+\mathrm{V}_{1}}{\mathrm{U}_{1}+\mathrm{V}_{2}}
$$

where $U_{1}$ is the sum of the products of concentration and mobility of all the cations present in solution $\mathrm{I} . \quad \mathrm{U}_{2}$ is the same sum for the other solution. $V_{1}$ and $V_{2}$ are the corresponding quantities for the anions.

It now remains to consider how closely our actual cells approach each of the assumptions involved in the derivation of the formula.

Planck's reasoning is based on the assumption that the intermediate layer is produced by diffusion alone, $i$.e., the two solutions are first brought together with a sharp boundary, and then an intermediate layer is produced by diffusion without mechanical mixing. He concludes that the rate of diffusion at first will be very great, but after diffusion has proceeded for a short time, the rate of diffusion becomes so small that the amount of diffusion is negligible in the time required to measure the potential. He also concludes that the potential is independent of the thickness of the intermediate layer, but depends only on the composition of the end solutions. A junction within a ground-glass joint, such as we used, seems to us to meet this condition as perfectly as it is possible to do so experimentally. Some of our cells, after showing a variable potential for the first hour or two after they were set up, remained constant for a week, which is quite in accord with Planck's conclusions from his mathematical analysis of the problem.

Henderson ${ }^{3}$ has attacked the problem by a thermodynamic process of

${ }^{1}$ Planck restricts his treatment to solutions in which all the ions are univalent. The more general case, which is much more complex mathematically, has been treated by Pleÿel, Z. physik. Chem., 72, I (1910), and by K. R. Johnson, Ann. Physik., 14, 995 (1904), but does not concern us for the present purpose.

${ }^{2}$ In our cells the concentration of the ions is not identical on the two sides of the junction, owing to a slight change in volume, which occurs on dissolving iodine, and to a slightly different degree of dissociation of potassium iodide and triiodide. We have, therefore, carried out the calculations with Planck's general equation, and obtained a result which differs by only 0.01 .millivolt from the result given by the simplified form.

${ }^{3}$ P. Henderson, Z. physik. Chem., 59, I 18 (1907); 63, 325 (1908). 
reasoning. He derives the same differential equation for the potential between two solutions differing in concentration by infinitesimal amounts that Planck obtained by kinetic reasoning. In order to integrate this equation, he assumes that the intermediate layer is formed, not by diffusion, but by the mechanical mixing of the end solutions. The last two assumptions made by Planck must also be made in Henderson's deduction. For the general case, the liquid potentials calculated by Henderson's equation and Planck's equation are appreciably different, but for the special case, met with in our cells, namely, the two end solutions containing a common cation $\left(\mathrm{K}^{+}\right)$at the same concentration, and differing only in the anions ( $\mathrm{I}^{-}$in one case, and a mixture of $\mathrm{I}^{-}$and $\mathrm{I}_{3}^{-}$in the other), Henderson's equation reduces to a form which is identical with Planck's equation. This shows that if a little mixing occurred in making our junction, it would not affect the results.

It seems probable that as the $\mathrm{I}_{3}-$ ion and $\mathrm{I}_{2}$ and $\mathrm{KI}$ molecules diffuse into the pure potassium iodide solution, the reversible reaction $\mathrm{I}^{-}+\mathrm{I}_{2} \longleftrightarrow \mathrm{I}_{3}$ may cause some change in the concentrations of the ions, and thus in effect change the nature of the intermediate layer. Since we do not know the relative rate of diffusion of the triiodide ion $\left(\mathrm{I}_{3}{ }^{-}\right)$and molecular iodine $\left(I_{2}\right)$, it is not possible to determine the influence of this on the intermediate layer. It is, therefore, reassuring that the Planck and Henderson equations, which assume quite different intermediate layers, give identical results for our special case.

The second assumption is not strictly met by our cells, since there is a slight difference in the viscosity of the two solutions, but we have convinced ourselves by suitable computations that this effect is so small that it may safely be neglected.

The third assumption is not met exactly even by dilute solutions. The "activity," to use the term proposed by G. N. Lewis, is not strictly proportional to the concentration. In the light of our present knowledge, however, it does not seem feasible to avoid the error inherent in this assumption. ${ }^{1}$

The values for the mobilities and concentrations of the ions used in this computation at $0^{\circ}$ have been determined by a special investigation, carried out for the purpose, and recently published. ${ }^{2}$ The corresponding data for $25^{\circ}$ are based upon the data of Bray and MacKay, ${ }^{3}$ corrected for the effect of viscosity. ${ }^{2}$

1 Experiments are under way, which, it is hoped, will throw more light on this question. But since this is a large problem in itself, which must require some time for completion, and since the outcome cannot affect the main conclusions of this paper, it has not seemed wise to postpone publication of the results already obtained, pending the outcome of this further study.

2 Jones and Hartmann, This JourNal, loc, cit.

${ }^{3}$ Bray and MacKay, This Journal, 32, 914 (IgIo). 
The Osmotic Work Correction.-The measured potential of the silver iodide cell must be further corrected on account of the osmotic work. In the reaction in the cell, iodide ion is produced (at the iodine electrode) in a solution of one concentration with respect to this ion, while a corresponding amount of iodide ion is removed (as silver iodide) at the other electrode from a solution almost twice as concentrated in iodide ion. This involves some osmotic work, which is included in the measured potential of the cell, and must be taken into consideration.

The familiar Nernst concentration cell equation is the most accurate method, according to our present knowledge, of calculating this potential.

$$
\left(\mathrm{E}_{2}-\mathrm{E}_{1}\right)=\mathrm{RT} / \mathrm{F} \text { in } \mathrm{C}_{\mathrm{I}}^{\prime}-\mathrm{C}_{\mathrm{I}_{\mathrm{I}}}^{\prime} \text {. }
$$

$\mathrm{C}^{\prime}{ }^{-}=$Concentration of iodide ion in potassium iodide solution.

$\mathrm{C}^{\prime \prime}{ }^{-}=$Concentration of iodide ion in same solution saturated with iodine.

This equation is obtained by the integration of a differential equation, which is derived thermodynamically and is doubtless accurate, but in order to integrate the equation in the form given, it is necessary to assume that the simple van't Hoff law holds. This assumption probably is not fulfilled exactly by our solutions, so that this correction may not be quite accurate. This potential due to osmotic work is in the same direction as the measured potential, and hence should be subtracted from the measured potential of the cell.

The potentials of the cell under the four conditions are given in Tabie $V$. In this table are also given the corrections which must be applied to the measured potentials, and the final corrected potentials, which represent the tendency of iodine and silver to combine with each other.

TABLE V.

\begin{tabular}{|c|c|c|c|c|}
\hline \multirow{2}{*}{ Measured potential (volts) ...... } & \multicolumn{2}{|c|}{ At $0^{\circ}$. } & \multicolumn{2}{|c|}{ At $25^{\circ}$. } \\
\hline & $\begin{array}{r}0.1 N . \\
+0.6936\end{array}$ & $\begin{array}{c}0.5 \mathrm{~N} . \\
+0.6920\end{array}$ & $\begin{array}{r}0.1 \mathrm{~N} \\
+0.7000\end{array}$ & $\begin{array}{c}0.5 \mathrm{~N} . \\
+0.6092\end{array}$ \\
\hline Liquid junction correction (volts). & +0.0030 & +0.0029 & +0.00325 & +0.0032 \\
\hline Osmotic work correction (volts)... & -0.0154 & -0.01 & -0.0180 & $\longrightarrow 0.0177$ \\
\hline inal corrected potential & +0.6812 & +0.6798 & $+0.685^{2}$ & +0.6847 \\
\hline Free energy (A) kilojoules......... & 65.73 & 65.60 & 66.12 & 66.07 \\
\hline Free energy (A) kilogram calories... & I $5 \cdot 72$ & 15.69 & $15.8 \mathrm{I}$ & 15.80 \\
\hline
\end{tabular}

Temperature coefficient of electromotive force from measurements with o. I $N$ solution $=(0.6852-0.68 \mathrm{I} 2) / 25=+0.000160$ volt per degree, equivalent to 15.5 mayers or 3.7 calories per degree.

Temperature coefficient of electromotive force from measurements with $0.05 \mathrm{~N}$ solution $=(0.6847-0.6798) / 25=+0.000196$ volt per degree, equivalent to I 8.9 mayers or 4.5 calories per degree.

The difference between the results with $0.1 N$ and $0.05 N$ solutions is probably due to the fact that the activity of the ions is not proportional to the concentration, especially in the stronger solution. This subject 
has been discussed in considerable detail by Bray and MacKay, whose conclusion is, "It is evident that, no matter what assumption is made, one or more of the substances involved will show marked deviations from the law of the ideal solution that activity and concentration are equal." Since these deviations are undoubtedly less in the more dilute solution, we regard the result obtained with the $0.05 N$ solution as the more reliable, although the result with the stronger solution furnishes a valuable confirmation.

These results show conclusively that the temperature coefficient of the free energy of formation of silver iodide is positive, and thus support the analysis of the coefficients of expansion based on Richards' hypothesis of compressible atoms, and furnish us with a reasonable explanation of this almost unique property of silver iodide.

\section{Free Energy, Total Energy, and Heat Capacity.}

His conception of the compressible atom led Richards ${ }^{1}$ to some new fundamental ideas regarding the relationship between the attracting energy or chemical energy, the free energy or power of producing outside work, and the heat evolved during a reaction, when it proceeds isothermally and under such conditions that no outside work is done.

"When the heat capacity of a system does not change during a reaction, and concentration influences are balanced, the free-energy and total-energy changes of the reaction are equal and unchangeable with the temperature, and each may be supposed to represent the total 'attracting energy' - a term which covers gravitational and electrical attraction as well as purely chemical attraction."

Richards pointed out that the compression which usually occurs during a chemical reaction must diminish the heat capacity by restricting the vibrations, so that the heat present in the factors before the reaction is more than sufficient to raise the temperature of the products from absolute zero to the temperature of the reaction. Therefore, the heat evolved during the reaction, as measured in the usual way in a calorimeter, is greater than the heat produced from the chemical energy of the reaction. Or, in other words, the "Wärmetönung" is greater than the chemical energy. In such a case, the free energy is less than the chemical energy, since a part of the chemical energy is expended in producing the compression of the atoms, and is not available for outside work. Since $d \mathrm{U} / d \mathrm{~T}=$ $\mathrm{C}_{F}-\mathrm{C}_{\mathrm{P}}$ (molecular heat capacity of factors minus molecular heat capacity of products), and $\mathrm{C}_{F}$ is greater than $\mathrm{C}_{\mathrm{P}}, d \mathrm{U} / d \mathrm{~T}$ will be positive. Richards reasoned that in such a case $d \mathrm{~A} / d \mathrm{~T}$ is negative, and was able to support this conclusion by experimental evidence. The possibility of the converse case is also clearly indicated by Richards, although such cases are much rarer.

One of these converse cases is silver iodide, a most interesting substance

1 Proc. Amer. Acad., 38, 293 (1902). 
from the standpoint of this hypothesis, because it has several exceptional properties; and one which is almost unique. ${ }^{1}$ During the formation of silver iodide from its elements, there is an increase in volume of nearly $15 \%$ of the whole, in contrast to most salts, which show a decrease in volume during formation. ${ }^{2}$ The molecular heat capacity of silver iodide is greater than the sum of the heat capacities of silver and iodine, ${ }^{3}$ which is also unusual, but is related to the increase in volume, as already pointed out in the discussion of the more common converse case. By reference to Table V; it will be seen that the free energy of formation of silver iodide (A) is 66. I kilojoules at $25^{\circ}$. It is easily possible to compute by the Helmholtz equation from the data presented in Table $\mathrm{V}$ that the heat evolved (U) is 61.0 kilojoules. $\mathrm{A}$ is, therefore; greater than $\mathrm{U} . d \mathrm{U} / d \mathrm{~T}$ is negative and $d \mathrm{~A} / d \mathrm{~T}$ is positive, and the coefficient of expansion is negative. These facts in regard to silver iodide thus confirm conclusions which Richards drew from the hypothesis of compressible atoms in a complete and remarkable way. The case is all the more noteworthy, because the relations are just the converse of those usually met with, but it is nevertheless entirely consistent.

In order that a qantitative formulation of these relationships may be subjected to a rigid test in many cases, it is necessary to know the atomic and molectular heat capacities of both factors and products of the reactions under consideration from absolute zero up to the working temperatures. Richards and Jackson 4 began the collection of the data on specific heats of solids down to liquid air temperatures, and in 19 Io published results on twenty-six elements. These results showed that the specific heats are very much less at low temperatures than at room temperature.

Richards first published these new fundamental ideas in regard to the "Significance of Changing Atomic Volume" in 1902. Nernst ${ }^{5}$ attempted, in 1906 , to give these ideas a mathematical formulation. But in doing this he made two assumptions which require experimental proof. These assumptions will be discussed in detail after Nernst's mathematical formt1lation has been followed to the point where these assumptions are necessary for further progress.

In his early papers, Nernst expressed the atomic or molecular heat capacities of solids as a function of temperature in the form of a rapidly

${ }^{1}$ Richards and Jones, This Journal, 3I, I86 (I909).

${ }^{2}$ Density................... Ag, I0.49 I, 4.993 AgI, 5.674

Molecular volume............ Ag, 10.28 I, 25.73 AgI, 41.38

$41.38-(10.28+25.73)=5.37 \mathrm{cc}$. increase in volume during formation of salt.

${ }^{3} \mathrm{~A}$ discussion of the experimental evidence for this statement will be found on a later page.

${ }^{4}$ Richards and Jackson, Z. physik. Chem., 70, 414 (1910).

${ }^{5}$ Nernst, Göttinger Nachrichten, 1906, I. 
convergent polynomial series in powers of $T$, but this expression was later abandoned in favor of Einstein's specific heat formula, and this in turn was superseded by a new specific heat formula proposed by Nernst and Lindemann.

In 1907, Einstein ${ }^{1}$ had derived the following expression for the atomic or molecular heat capacity of solids at constant volume as a function of the absolute temperature and the "vibration frequency" of the atoms (or electrons within the atoms).

$$
\mathrm{C}_{v}={ }_{3} \mathrm{R} \Sigma \frac{(\beta \nu / \mathrm{T})^{2} e^{\beta \nu / \mathrm{T}}}{\left(e^{\beta \nu / \mathrm{T}}-\mathrm{I}\right)^{2}}
$$

$\mathrm{C}_{y}=$ atomic (or molecular) heat capacity at constant volume.

$\mathrm{R}=$ gas constant.

$e=$ base of natural logarithns.

$\top=$ absolute temperature.

$\beta=4.86 \times 10^{-11}$, a universal constant, whose numerical value was deduced by Planck from a study of radiation phenomena.

$\nu$ = vibration frequency theoretically, but in practice is usually selected empirically to make the formula fit the data as well as possible.

$\Sigma$ = the summation sign which indicates that summation is to be extended over the vibrations of all the frequencies which are actually occurring.

This formula was deduced by applying the Quanten Hypothesis, which Planck formulated for the ether vibrations, to the vibrations of solids. The assumption is made that the atoms of a solid cannot take up heat continuously, ${ }^{2}$ but only in units or "quanta," and that the magnitude of the units is proportional to the vibration frequency.

The heat capacity at constant volume $\left(\mathrm{C}_{v}\right)$ cannot, however, be determined experimentally. The heat capacity at constant pressure $C_{p}$, which can be experimentally determined, and is desired in the development of the theory, can, however, be computed from $\mathrm{C}_{\text {o }}$ by the following well known thermodynamic formula.

$$
\mathrm{C}_{p}=\mathrm{C}_{v}+9 \alpha^{2} \mathrm{VT} / \mathrm{K} \text {. }
$$

$\alpha=$ cubic coefficient of expansion (thermal)

$\mathrm{K}=$ coefficient of compressibility.

$\mathrm{V}=$ molecular volume.

Unfortunately we have little exact knowledge of $\alpha$ and $\mathrm{K}$ as functions of the temperature. Nernst and his co-workers replace the last term by $a^{T} \mathrm{~T}^{3 / 2}$ (where $a$ is constant for any substance), pointing out that this accords with what we know in regard to the influence of temperature on $\alpha$ and $\mathrm{K}$, and that this last term is small in comparison to the first term.

${ }^{1}$ Einstein, Ann. Phys., [4] 23, r8o (1907).

2 The word "continuously" is used in its mathematical sense. 
This formula was found to be in agreement with the early results obtained in Nernst's laboratory by Nernst, Eucken, Pollitzer, Koref, and Lindemann, which extended to liquid air temperatures only.

When, however, the measurements were extended down to the temperature of liquid hydrogen, it was found that the experimental results were unmistakably higher than the results computed from the Einstein formula. Nernst and Lindemann ${ }^{1}$ then proposed a modified formula

$$
\mathrm{C}_{p}=3 / 2 \mathrm{R} \Sigma\left\{\frac{(\beta \nu / \mathrm{T})^{2} e^{\beta \nu / \mathrm{T}}}{\left(e^{\beta \nu / \mathrm{T}}-\mathrm{I}\right)^{2}}+\frac{(\beta \nu / 2 \mathrm{~T})^{2} e^{\beta \nu / 2 \mathrm{~T}}}{\left(e^{\beta \nu / 2 \mathrm{~T}}-\mathrm{I}\right)^{2}}\right\}+a \mathrm{~T}^{3 / 2}
$$

which was found to fit the data very much better down to liquid hydrogen temperatures. This formula was originally found empirically, but Nernst and Lindemann point out that, if the assumption is made that the potential energy of the atom due to its separation from its position of rest is taken up in quanta which are one-half as great as the quanta of the kinetic energy, then this formula may be derived by reasoning very similar to that of Einstein. In the case of the metals it. was only necessary to assume a single value for $\nu$, and in the case of simple salts containing two elements, it was only necessary to assume two values of $\nu$ corresponding to the two kinds of atoms. Two values of $\nu$ are assumed in the case of sulfur arid graphite, but only one for diamond. Three values of $\nu$ are assumed in the case of silica and mercurous sulfate.

According to this formula, the heat capacities approach zero as their limit, as the temperature approaches absolute zero. This remarkable result has been experimentally confirmed by Nernst ${ }^{2}$ and Lindemann in the case of the diamond. According to this formula, $\mathrm{C}_{v}$ approaches $3 \mathrm{R}$ as its limit, as the temperature is raised. This is in entire accord with the conclusions reached previously by G. N. Lewis, ${ }^{3}$ that the deviations from Dulong and Petit's Law are due partly to the second term involving the heat absorbed during thermal expansion, and in the case of a few elements to the necessity of reaching high temperatures, before Dulong and Petit's Law holds. Moreover, we have convinced ourselves by suitable calculations, that the formula can be made to fit, at least approximately, the data of Richards and Jackson, and Griffiths and Griffiths. ${ }^{4}$

In the case of three salts $(\mathrm{KCl}, \mathrm{KBr}$ and $\mathrm{NaCl})$ the value of the vibration frequency may be computed from the measurements of the wave lengths of the residual rays (Reststrahlen) by Rubens and Hollnagel. ${ }^{5}$

${ }^{1}$ Nernst and Lindemann, Sitzb. Akad. Wiss. Berl., I911, 494; Z. Elektrochem., I7, 817 (1911).

${ }^{2}$ Nernst and Lindemann, Loc. cit.

3 This JoUrnal, 29, I I65 (I907).

- Phil. Trans., (A) 213, 119 (1913); Proc. Roy. Soc. London, (A) 90, 557 (1914).

5 Sitzb. Akad. Wiss. Berl., 1910, 26; Vdlg. d. D. phys. Ges., 12, 83 (1910). 
Since the other quantities in the formula are all known for these salts, it has been possible to compute the heat capacity without selecting any quantity empirically to fit the data. The calculated results accord with the observed within $1 \%$, which must certainly be regarded as a great triumph for the formula.

The assumption of a single vibration frequency seems a priori very improbable in view of the fact that solids show a continuous spectrum. Three attempts to derive a specific heat formula with the aid of the Quanta theory, without using the simplifying assumption that one or two vibration frequencies only are involved, have been published by Debye, ${ }^{1}$ Born and von Karman, ${ }^{2}$ and vor Juptner. ${ }^{3}$ Von Juptner's formula leads to negative values for $\mathrm{C}_{v}$ in certain intervals of temperature, and may, therefore, be dismissed at once. Debye's formula and Born and von Karman's formula both give specific heat curves which are very similar to those given by the Nernst-Iindemann formula. All of them give $\mathrm{C}_{\nu}$ rather than $\mathrm{C}_{p}$.

The formula of Debye is

$$
\begin{aligned}
& \mathrm{C}_{v}={ }_{3} \mathrm{R}\left\{\frac{4}{5} \pi^{4}\left(\frac{\mathrm{T}}{\beta \nu}\right)^{3}-\frac{3 \beta \nu / \mathrm{T}}{e^{\beta \nu / T}-\mathrm{I}}\right. \\
& \left.\rightarrow \mathrm{I} 2 \beta \nu / \mathrm{T} \sum_{n=1}^{n=\infty} e^{-n \beta \nu / \mathrm{T}}\left(\frac{\mathrm{I}}{n \beta \nu / \mathrm{T}}+\frac{3}{n^{2}(\beta \nu / \mathrm{T})^{2}}+\frac{6}{n^{3}(\beta \nu / \mathrm{T})^{3}}+\frac{6}{n^{4}(\beta \nu / \mathrm{T})^{4}}\right)\right\} .
\end{aligned}
$$

This formula was shown by Debye to give results almost identical with those of the Nernst-Iindemann formula, except at very low temperatures, where it gives higher results. Nernst and Lindemann have carried out the laborious computations necessary to compare the results obtained with this formula and with their own formula with experimental results in the cases of aluminum, copper, silver, diamond, potassium chloride, and sodium chloride. They conclude that the new Debye formula is slightly better than their own. However, a careful examination of the results of these computations shows that the advantage of the Debye formula is very small, if it exists at all. The two formulas agree with each other much better than either agrees with the experimental results, and each has the advantage in about one-half of the cases, and they, therefore, may be regarded as practically identical, until data are available which are accurate enough to make possible a choice between the two formulas.

In the following mathematical development of the theory and the computations based thereon, we have used the Nernst-Lindemann formula in preference to the Debye because ${ }_{2}$ of its much simpler mathematical form,

${ }^{1}$ Ann. Physik., 39, 789 (I912).

Physik. Z, 13, 308 (1912).

- Z. Elektrochem. 19, 7 I I (1913). 
and because it is the form used by Nernst and his students to test the theory. ${ }^{1}$

So many doubtful assumptions are involved in the derivation of the Nernst-Lindemann formula that it seems to us best to regard it simply as an empirical formula, in which the numerical value of $a$ and one or more values of $\beta \nu$ are selected arbitrarily to fit the data as well as possible. There can be no doubt that a polynomial series in powers of $T$ would require many more empirical constants to make it fit the data as well.

By Kirchhoff's Law

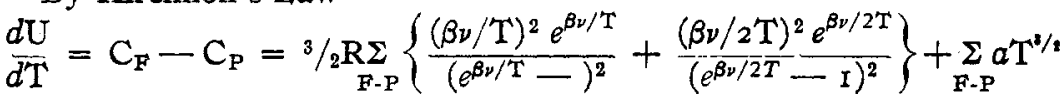

$U$ is the heat evolved when the reaction proceeds isothermally in such a way that no external work is done. If only solids are involved in the reaction, and the pressure is not over one atmosphere, the external work due to changes in volume during the reaction may be neglected.

$C_{F}$ and $C_{P}$ are the heat capacities of the factors and the products of the reaction, respectively, at constant pressure.

Integrating:

$$
\cdot \mathrm{U}=\mathrm{U}_{0}+8 / 2 \mathrm{R} \Sigma\left(\frac{\beta \nu}{\mathrm{F} \cdot \mathrm{P}}\left\{\frac{\beta \nu}{e^{\beta v / T}-\mathrm{I}}+\frac{\beta \nu}{2\left(e^{\beta \nu / 2 \mathrm{~T}}-\mathrm{I}\right)}\right\}+\sum_{\mathrm{F}-\mathrm{P}} 2 / 5 a \mathrm{~T}^{s / 3}\right.
$$

$U_{0}$ is an integration constant, but if we place $T=0$ in this expression, all other terms vanish, and it is, therefore, the heat evolved at absolute zero.

$$
\mathrm{A}-\mathrm{U}=\mathrm{T} d \mathrm{~A} / d \mathrm{~T}
$$

where $A$ is the maximum amount of external work which can be done by the chemical reaction. In the case under consideration, this work is all electrical work.

$$
\begin{aligned}
& \frac{A d T-T d A}{T^{2}}=\frac{U d T}{T^{2}} \\
& -d\left(\frac{A}{T}\right)=\frac{U d T}{T^{2}} .
\end{aligned}
$$

Before we can integrate, it is necessary to express $U$ as a function of $T$ by means of Equation 2.

$$
\begin{aligned}
& -d\left(\frac{\mathrm{A}}{\mathrm{T}}\right)=\frac{\mathrm{U}_{0} d \mathrm{~T}}{\mathrm{~T}^{2}}+{ }^{3} / 2 \mathrm{R} \underset{\mathrm{F} \cdot \mathrm{P}}{\Sigma}\left\{\frac{\beta \nu d \mathrm{~T}}{\mathrm{~T}^{2}\left(e^{\beta \nu / \mathrm{T}}-\mathrm{I}\right)}+\right. \\
& \left.\frac{\beta \nu d \mathrm{~T}}{2 \mathrm{~T}^{2}\left(e^{\beta \nu / 2 \mathrm{~T}}-\mathrm{I}\right)}\right\}+\sum_{\mathrm{F}-\mathrm{P}}{ }^{2} / 5 a \mathrm{~T}^{\mathrm{1} / 2} d \mathrm{~T} .
\end{aligned}
$$

${ }_{1}$ Nernst has published the calculations with the Debye formula in one case only as far as we have been able to find. Fortunately for our purposes, the case chosen was the formation of silver iodide, in which we are especially interested. This calculation showed that the results for $A$ and $U$ are practically identical, using either the NernstLindemann or the Debye formula. Nernst says "bei der Berechnung chemischer Affinität von kondensierten Systemen sind wohl bei allen Temperaturen (vielleicht ganz extreme Fälle ausgenommen) die Differenzen praktisch belanglos." Sitzb. Akad. Wiss. Berlin, r9ז2, II 74 . 
Integrating

$$
\begin{aligned}
& -\frac{\mathrm{A}}{\mathrm{T}}=-\frac{\mathrm{U}_{0}}{\mathrm{~T}}-\mathrm{I}+{ }^{3} /{ }_{2} \mathrm{R} \underset{\mathrm{F}-\mathrm{P}}{\Sigma}\left\{\frac{\beta \nu}{\mathrm{T}}-\ln \left(e^{\beta \nu / \mathrm{T}}-\mathrm{I}\right)+\right. \\
& \left.\frac{\beta \nu}{2 \mathrm{~T}}-\ln \left(e^{\beta \nu / 2 \mathrm{~T}}-\mathrm{I}\right)\right\}+\underset{\mathrm{F}-\mathrm{P}}{\Sigma} 4 / 15 \mathrm{~T}^{8 / 2} . \\
& \mathrm{A}=\mathrm{U}_{0}+\mathrm{IT}-3 /{ }_{\mathrm{F}} \mathrm{R} \underset{\mathrm{F}-\mathrm{P}}{\Sigma}\left\{3 / 2 \beta \nu-\mathrm{T} \ln \left(e^{\beta \nu / \mathrm{T}}-\mathrm{I}\right)-\right. \\
& \left.\mathrm{T} \ln \left(e^{\beta \nu / 2 \mathrm{~T}}-\mathrm{I}\right)\right\}-\underset{\mathrm{F} \cdot \mathrm{P}}{\Sigma} 4 / 15 a \mathrm{~T}^{6 / 2}
\end{aligned}
$$

Differentiating

$$
\begin{aligned}
\frac{d \mathrm{~A}}{d \mathrm{~T}}=+\mathrm{I}-3 / 2 \mathrm{R} \sum_{\mathrm{F}-\mathrm{P}}\left\{3 / 2 \frac{\beta \nu}{\mathrm{T}}-\ln \left(e^{\beta \nu / \mathrm{T}}-\mathrm{I}\right)+\frac{\beta \nu / \mathrm{T}^{\mathrm{T}}}{e^{\beta \nu / \mathrm{T}}-\mathrm{I}}\right. \\
\left.-\ln \left(e^{\beta \nu / 2 \mathrm{~T}}-\mathrm{I}\right)+\frac{\beta \nu / 2 \mathrm{~T}}{e^{\beta \nu / 2 \mathrm{~T}}-\mathrm{I}}\right\}-\underset{\mathrm{F} \cdot \mathrm{P}}{\sum}{ }^{2} / 3{ }^{2} \mathrm{~T}^{3 / 2} .
\end{aligned}
$$

I is an integration constant, which is thermodynamically indeterminate, and whose physical significance is by no means clear. ${ }^{1}$ The presence of this constant in the equation for $\mathrm{A}$ and $d \mathrm{~A} / d \mathrm{~T}$ makes it impossible to compute the free energy from data on specific heats and thermochemical data alone, but makes it necessary to determine A experimentally for some one temperature at least. This very greatly restricts the usefulness of the equation, because there are many reactions for which the thermochemical and specific data are available or readily obtainable experimentally, whose free energy cannot be determined by any means known to us at the present time.

The two fundamental assumptions made by Nernst, and which constitute the essence of the so-called Nernst Heat Theorem, are

and

$$
\lim _{T=0}\left(\frac{d U}{d T}\right)=0
$$

$$
\lim _{T=0}\left(\frac{d \mathrm{~A}}{d \mathrm{~T}}\right)=0
$$

These assumptions apply only to reactions taking place in "condensed systems," i. e., in systems involving only solids and liquids, but no gases or solutions. The possible truth of these relationships was clearly foreshadowed by Richards, ${ }^{2}$ but at the time very few data were available on specific heats at low temperatures so that a rigid test of these ideas was impossible. Does the new evidence made available since 1902 en-

${ }^{1}$ Lewis, This Journal, 35, 29 (1913). Haber "Thermodynamics of Technical Gas Reactions" translation by A. B. Lamb, p. 4 Iff.

${ }^{2}$ See especially Proc. Amer. Acad,, 38, 302 (1902), and Z. physik. Chem., 42, 138 (1902). 
able us to advance beyond the conservative position taken by Richards at that time?

If the specific heats of all solids approach the same limit zero, as we approach absolute zero, as required by the Nernst-Lindemann formula, and as found experimentally in the case of the diamond, then the first assumption follows as a necessary consequence by Kirchhoff's Law.

If in the expression for $d \mathrm{~A} / d \mathrm{~T}$ we place $\mathrm{T}=0$, everything vanishes except the term $+I$, leaving $\lim _{\mathrm{T}=0}\left(\frac{d \mathrm{~A}}{d^{\top} \mathrm{T}}\right)=\mathrm{I}$.

Therefore, if we accept the Nernst-Iindemann ${ }^{1}$ specific heat formula as valid down to absolute zero, then a mathematically equivalent way of stating the second of Nernst's assumptions for condensed systems is $I=0$. This is very important, if it can be proved, because it makes it possible to calculate, from thermal data alone, the free energy of any reaction, and hence the equilibrium constant of the reaction, and the electromotive force of a galvanic cell. This assumption has been referred to by some of Nernst's disciples ${ }^{2}$ as the Third Law of Thermodynamics. But as the First and Second Laws of Thermodynamics were established only by extensive experimental evidence, similar evidence will be required to justify this title.

Nernst's second assumption may be tested by the data presented in this paper, measurements of the heat capacities of silver, iodine, and silver iodide made by Nernst $^{3}$ being accepted.

The following table shows the values of $\beta \nu$ and $a$, which have been selected by Nernst in order to make the results computed with the NernstLindemann formula agree as well as possible with the experimental results.

\begin{tabular}{|c|c|c|}
\hline & $\beta_{\nu}$ & a \\
\hline $\mathrm{Ag}$. & $22 \mathrm{I}$ & 0.000048 \\
\hline I.... & 98 & 0.000100 \\
\hline AgI. & 220 and 70 & 0.00020 \\
\hline
\end{tabular}

In the case of silver, the calculated and observed results agree within about I\%. These results are also confirmed, at least down to liquid air temperatures, by the results of Richards and Jackson, and Griffiths and Griffiths within $I \%$. The results on silver iodide agree with those computed from

${ }_{1}$ The same would be true for any other specific heat formula, which would yield a function in the equation for $d \mathrm{~A} / d \mathrm{~T}$ which vanishes when $\mathrm{T}=0$. This would be true for the Debye formula, or for a formula having the form of a convergent polynomial series $\mathrm{C}_{p}=a+b \mathrm{~T}+c \mathrm{~T}^{2}+\ldots \ldots$, in which the first term $a$ is zero in accordance with Nernst's first assumption.

${ }^{2}$ For example, Karl Jellinek, "Physikalische Chemie der homogenen und heterogenen Gasreaktionen unter besonderer Berücksichtigung der Strahlungs- und Quantenlehre sowie des Nernstschen Theorems." (Book published by Hirzel, Leipzig, rgr3, p. 478 .)

${ }^{3}$ Ann. Physik., 36, 395 (I9II). 
the formula nearly as well. Recently a new series of results on silver iodide has been published by Nernst and Schwers, ${ }^{1}$ using a much modified apparatus. By plotting the new results and the old results $\left(C_{p}\right.$ against $\left.T\right)$ it becomes evident that the new and the old results do not agree well with each other, and moreover the curve depicting the new results has an abnormal and unusual shape. ${ }^{2}$ Moreover no new results on iodine and silver obtained by the new method are available, and it, therefore, seems best to use the old results in this computation. In the case of iodine, the agreement is not so close, discrepancies of $\pm 3 \%$ being common, and at the lowest temperature $\left(28.3^{\circ} \mathrm{A}\right)$, the discrepancy is $6 \%$.

Estreicher and Staniewski ${ }^{3}$ have measured the average specific heat of iodine from $-190^{\circ}$ to $+17^{\circ}$ and from $-80^{\circ}$ to $+17^{\circ}$. Their result is ${ }_{2} \%$ higher than that computed from the Nernst-Iindemann equation using the above values of $\beta \nu$ and $a$.

A plot of these results shows very clearly that the heat capacity of silver iodide exceeds the sum of the heat capacities of silver and iodine.

The best way to test the question whether or not $I=0$ is to substitute the above values of $\beta \nu$ and $a$ in Equation 9, which gives the following results:

at $0^{\circ} \mathrm{dA} / d^{\prime} \mathrm{T}=\mathrm{I}+2.18$ calories per degree;

at $25^{\circ} \mathrm{dA} / d \mathrm{~T}=\mathrm{I}+2.20$ calories per degree.

But the value found experimentally with $0.05 \mathrm{~N} \mathrm{Kl}$ solution was

$d \mathrm{~A} / d \mathrm{~T}=4.52$ calories per degree

hence $I=4.52-2.19=+2.33$ calories per degree.

This may be checked in another way by using Equation 8 , which gives the following results:

$$
\begin{aligned}
& A_{273}=U_{0}+I \times 273+5 \text { Io calories: } \\
& A_{298}=U_{0}+I \times 298+565 \text { calories. }
\end{aligned}
$$

But according to our measurements with $0.05 \mathrm{~N}$ solution

$$
\begin{aligned}
& A_{273}=I_{5} 687 \text { calories. } \\
& A_{298}=I_{5} 5800 \text { calories. }
\end{aligned}
$$

Then solving these two equations simultaneously, we obtain $I=2.33$ and $U_{0}=14541$, and since $273 \times 2.33=636$, the term IT, which Nernst assumes to be zero and discards, is greater than the sum of all the terms involving the $\beta \nu$ and $a$ of the Nernst-Lindemann specific heat formula.

In an exactly similar way we may carry out the computations with our results obtained in $0.1 N$ solution, for which the experimental value of

${ }_{1}$ Sitzb. Akad. Wiss. Berlin, I913, 367.

2 The increase in $C_{p}$ with the temperature is very great up to $85.2^{\circ} \mathrm{A}$, and then becomes untusually small, giving a sharp bend in the curve which is abnormal. The curve for the old results has the shape commonly found in such curves.

${ }^{3}$ Bull. Akad. Cracovie, I912, 834. 
$d \mathrm{~A} / d \mathrm{~T}=3.679$, which gives $\mathrm{I}=\mathrm{I} .50$, and $\mathrm{U}_{0}=\mathrm{I} 4800$. This, however, is believed to be less reliable than the results with the more dilute solution. It should be noticed that the more dilute solution, in which the activity of the ions is more nearly proportional to the concentration, shows the higher value of $I$.

A quite different procedure is sometimes adopted in papers from Nernst's laboratory to prove that. $I=0$. Equation 8 is used (with the term IT missing, which, of course, involves the assumption that $I=0$ ), to calculate a numerical value of $U_{0}$ from the experimentally determined value of $A$ at one temperature. Then, using this value of $U_{o}$, the numerical value of $U$ is computed by means of Equation 2, and this value is compared with the experimentally determined value of $U$. But since the exact value of $U$ is often in doubt by many hundred calories a rigid test of the fundamental assumption is not secured. Or the procedure may be reversed by calculating $\mathrm{U}_{0}$ from $\mathrm{U}$ by Equation 2 and then calculating A from Equation 8 (with the term IT missing). In either case the uncertainty in $U$ makes a rigid test impossible.

An examination of Equation 9 shows that $U_{0}$ has been eliminated and that, therefore, what is really needed to secure a more direct determination of the value of $I$ is a determination of the temperature coefficient of the free energy. Since electromotive force measurements are, in general, more precise than calorimetric measurements, and since in a comparison of very similar measurements made at slightly different temperatures, systematic errors are largely eliminated, unless these errors have an appreciable temperature coefficient, we conclude that the value of I can best be determined by means of data on the temperature coefficient of the electromotive force of galvanic cells. It is obvious from Equation 9 that an accurate determination of the temperature coefficient is of primary importance in testing the Nernst Heat Theorem.

There still remains the possibility that I might be made equal to zero by a slight change in $\beta \nu$ and $a$, which would still give calculated values for the specific heats which were within the limit of accuracy of the experimental determinations of specific heats.

In order to test this possibility we assume the $\beta \nu$ and $a$ values for silver and silver iodide to be correct, because these agree with the formula best, and find by trial that, if we assume for iodine $\beta \nu=143$ and $a=0.00007$, then the computed value of $d \mathrm{~A} / d \mathrm{~T}$ becomes +4.5 , which makes $\mathrm{I}=0$. Then we compute the atomic heat capacity of iodine from these values, which shows that the computed results differ from the observed by an amount which is many times the experimental error. For example, at $28.3^{\circ} \mathrm{A}$, the computed value is $2.3^{\mathrm{I}}$ calories per degree, whereas the observed value is 3.78 , at $36.5^{\circ}$, the computed value is $3 . \mathrm{r}_{4}$, and the observed 
4.17 ; at $77^{\circ}$, the computed value is 5.07 , and the observed value 5.38 ; at $298^{\circ}$ the computed value is 6.21 and the observed 6.64 .

We, therefore, conclude that in the present state of our knowledge the variation of heat capacity with the temperature and with the available data on the heat capacities of the substances concerned, the evidence of the case is against the general theorem that $I=0$ in the case of all reactions between solids.

While the experimental work described in this paper was in progress, there appeared a paper by Ulrich Fischer, ${ }^{1}$ describing an experimental study of the same problem, as it was carried out in Nernst's laboratory. Fischer interprets his results as supporting the Nernst Heat Theorem. He found $d \mathrm{~A} / d \mathrm{~T}=2.4 \mathrm{I} 9$ calories per degree from his cells containing $0.5 N \mathrm{KI}, d \mathrm{~A} / d \mathrm{~T}=1.267$ from cells containing $1 / 3 N \mathrm{KI}$, and $d \mathrm{~A} / d \mathrm{~T}=$ I.66 from cells containing o. I $N \mathrm{Kl}$.

Fischer reports measurements on seven cells containing $0.1 N \mathrm{KI}$ at temperatures ranging from 14.2 to $40.2^{\circ}$, the results being best expressed by the equation, $\mathrm{E}=0.6916+0.000305 t$.

Fischer's cells were, however, less satisfactory than ours in constancy and reproducibility, the average difference of his 35 measurements from the mean expressed by the above equation being 0.9 millivolts, with a maximum difference of 2.8 millivolts, and 6 out of the 35 readings showing a difference of 2 millivolts or more. Our cells showed variations not more than 0.1 of this, and were about I millivolt higher. His cells containing $0.5 \mathrm{~N} \mathrm{KI}$ are even less reproducible, the average deviation from the mean being 1.15 millivolts, and the maximum 5.7 millivolts. Our experience leads us to infer that the cause of this irregularity in Fischer's cells was in the liquid junction. We constructed some cells like Fischer's, and found them not to be reproducible with an accuracy better than I millivolt.

Fischer makes no reference to the potential at the boundary of the two solutions, which has a value of about +3.0 millivolts at $0^{\circ}$, and +3.2 millivolts at $25^{\circ}$, thus raising the value of $d \mathrm{~A} / d \mathrm{~T}$.

In applying a correction for osmotic work, Fischer makes an error which makes his value of $d \mathrm{~A} / d \mathrm{~T}$ less than it ought to be. He assumes that all the iodine dissolved in potassium iodide solution is present as $\mathrm{KI}_{3}$. But, in the stronger solutions $(N / 3$ and $N / 2)$ the existence of higher complexes and the deviations of these solutions from the laws of dilute solutions cannot. be safely ignored. Furthermore, an appreciable part of the free iodine is present as $\mathrm{I}_{2}$, especially in the o. I $N$ solution, and, moreover, the amount present as $\mathrm{I}_{2}$ increases greatly with the tempera-

${ }_{1} Z$. anorg. Chem., 78, 4I (I9I2). 
ture, ${ }^{1}$ so that their neglect of this fact results in an error in their value for the temperature coefficient, $d \mathrm{~A} / d \mathrm{~T}$.

In order to apply this correction accurately, and to make the application of the liquid junction correction possible, a careful study of the conditions in solution of $\mathrm{K} 1$ saturated with iodine at $13.1^{\circ}, 23.9^{\circ}$ and $35.4^{\circ}$ should have been made by Fischer, similar to the work of Bray and Mackay at $25^{\circ}$, and Jones and Hartmann at $0^{\circ}$. An estimate based on these two investigations indicates very clearly that Fischer's rough method of applying the correction has made his temperature coefficient less than one-half of what it should be. In the discussion of Equations 8 and 9, it was pointed out that accuracy in the determination of the temperature coefficient is essential to make a test of the Nernst Heat Theorem of any value.

\section{Summary.}

The electromotive force of silver-silver iodide-iodine cells was measured at $0^{\circ}$ and $25^{\circ}$.

An improved method of preparing silver-silver iodide electrodes was devised.

An improvement in the constancy and reproducibility of the results was secured when the junction between the solutions around the electrodes was made to occur within a ground-glass joint.

The free energy of formation of silver iodide from silver and iodine is 65.1 kilojoules at $0^{\circ}$, and 66.I kilojoules at $25^{\circ}$.

These measurements show that the affinity of silver and iodine for each other increases with rising temperature, which makes possible a plausible explanation of the negative coefficient of expansion of silver iodide, and thus supports the analysis of coefficients of expansion based on the Richards' hypothesis of compressible atoms.

The heat of formation of silver iodide is $6 \mathrm{r} . \mathrm{o}$ kilojoules.

It is shown that the relationships between the properties and thermodynamic constants of silver iodide support many conclusions which Richards drew from his hypothesis of compressible atoms, bit that they do not support the second of the assumptions which Nernst applied to these conclusions, commonly known as the Nernst Heat Theorem.

It is shown that the best way to test the Nernst assumptions is by means of accurate determinations of the temperature coefficient of free energy, interpreted by Equation 9.

Cameridge, Mass.

1. The solubility of iodine in pure water in mols $I_{2}$ per liter is

$0^{\circ} \quad 0.000638$ Jones and Hartmann $\quad 35^{\circ} 0.00184$ Hartley and Campbell

$18^{\circ} 0.000709$ Hartley and Campbell $45^{\circ} 0.00255$ Hartley and Campbell

$25^{\circ} 0.00134$ Noyes and Seidensticker $55^{\circ} 0.00303$ Hartley and Campbell

Sammet, Hartley and Campbell, $60^{\circ} 0.004$ I6 Sammet Bray. 